\title{
Performance of Retaining Walls with Compressible Inclusions under Seismic Loading
}

\author{
Abdelkader Dram ${ }^{\text {a*}}$, Sadok Benmebarek ${ }^{\text {a }}$, Umashankar Balunaini ${ }^{\mathrm{b}}$ \\ ${ }^{a}$ Department of Civil Engineering and Hydraulic, NMISSI Laboratory, Biskra University, BP 145, Biskra 07000, Algeria. \\ ${ }^{b}$ Centre Department of Civil Engineering, Indian Institute of Technology Hyderabad, Kandi, Telangana 502 285, India.
}

Received 01 September 2020; Accepted 21 November 2020

\begin{abstract}
This paper investigates the possible application of recycled tyre shreds as compressible inclusion behind retaining walls under dynamic loading. It is a novel method to reduce the magnitude of earthquake-induced dynamic forces against rigid earth retaining wall structures. A numerical model to analyze the behavior of retaining walls with compressible cushion was developed in PLAXIS 2D, a two-dimensional finite element analysis based software, and the results were validated by comparison with experimental findings from physical models. The study evaluates the effects of thickness of compressible cushion and the friction angle of the backfill on the seismic performance of retaining walls. To assess the effect of frequency on wall performance with and without cushion, the wall was subjected to 15 cycles of sinusoidal excitation with acceleration amplitudes of $0.1 \mathrm{~g}$ to $0.3 \mathrm{~g}$ at a frequency of $7 \mathrm{~Hz}$. The results from the numerical analysis indicate that the permanent displacements of the wall were reduced in the range of $38 \%$ to $52 \%$ and the horizontal earth pressures were reduced by about $55 \%$ to $76 \%$ due to the presence of tyre shreds as a compressible cushion between the wall and backfill. Results showed that the dynamic load against the retaining wall can be considerably reduced through the proposed technique.
\end{abstract}

Keywords: Tyre Shreds; Compressible Inclusion; Retaining Walls; Finite Element Analysis.

\section{Introduction}

Earth retaining structures represent an essential component of many civil engineering works. These structures are used in numerous infrastructure projects and are designed to withstand lateral earth pressures due to backfill retained by them. However, the increased thrust of the backfill on the retaining walls can be mitigated by a lightweight, compressible material with high vibration absorption capacity, such as scrap tyre derived (STD) materials (tyre shreds, tyre chips and tyre crumbs), to achieve static stability. Recycle and reuse of a large quantity of waste tires in civil engineering projects can subscribe to a sustainable society. Among its several uses, tyre shreds and tyre chips were used as a compressible inclusion between the wall and backfill to reduce the lateral pressures [1-3].

Studies are also being carried out by various researchers encompassing laboratory studies and field applications to explore the use of scrap tires in civil engineering applications (for example, [4-6]). Humphrey and Manion [7] and Edil and Bosscher [8] have demonstrated that tire shreds and tire shred mixtures are highly compressible at low normal pressures. Ahmed et al. [9] reported that tyre sand-chip mixtures with weight ratios of 39\% exhibited excellent engineering properties, such as ease in compaction, low density, low compressibility, high strength, and excellent

* Corresponding author: abdelkader.dram@univ-biskra.dz

http://dx.doi.org/10.28991/cej-2020-03091631

(C) 2020 by the authors. Licensee C.E.J, Tehran, Iran. This article is an open access article distributed under the terms and conditions of the Creative Commons Attribution (CC-BY) license (http://creativecommons.org/licenses/by/4.0/). 
drainage characteristics. Cecich et al. [10] used tyre chips alone in the backfill of retaining wall and obtained higher safety factors against sliding and overturning compared to that when sand was used as backfill. Foose et al. [11] investigated the use of shredded waste tyres to reinforce sand, performed direct shear tests on tyre shred-sand mixtures. They reported that shear strength was considerably impacted by the normal stress, the content of tyre shreds, and unit weight of the sand matrix. They also reported friction angle as high as $67^{\circ}$ for sand reinforced by tyre shreds, while friction angle of sand alone was found to be $34^{\circ}$. Tweedie et al. [12] found that using tire shreds as a backfill material resulted in low earth pressures on the retaining wall, which allowed a decrease in the wall thickness. The seismic efficiency of retaining walls constructed with Tyre Derived Aggregate (TDA) was evaluated recently by Xiao et al. [13] and reported that wall displacements, accelerations, and dynamic backfill stresses were reduced noticeably by the use of TDA compared to those of conventional sand backfill.

Ahn and Cheng [14] found that slippage on the wall increased, but the dynamic pressure exerted on the wall with the TDA backfill decreased considerably by performing a large-scale shaking table test. Reddy and Krishna [15] and Dammala et al. [16] investigated the static and seismic behaviour of retaining wall backfilled with sand-tyre aggregate mixtures as backfill materials. Recent shaking table tests have been conducted by Hazarika et al. [2] on gravity-type model caisson shielded by a cushioning tyre chip, and reported that the presence of tyre chips lowered the seismic load against the caisson wall. Reddy and Krishna [3] reported using their experimental investigation that the horizontal displacements and lateral earth pressures are reduced to about 70-80\%, compared to those without compressible inclusion. Reddy and Krishna (2019) [17] studied the dynamic response of retaining wall models backfilled with different types of sand-tyre chips (STC) mixtures using a shaking table. They observed that the rubber content in sand causes up to $50 \%$ to $65 \%$ reduction in wall displacement and $70 \%$ to $80 \%$ reduction in dynamic earth pressure.

Lee and Roh [18] conducted numerical studies and field tests on concrete culverts backfilled with tyre chips and expanded polystyrene and showed that the use of tyre combination resulted in a lower dynamic earth pressure due to its lower modulus of elasticity and its higher damping ratio compared to expanded polystyrene Ravichandran and Huggins [19], and Shrestha et al. [20] performed dynamic finite element analyses of retaining walls backfilled with tyre shreds and clean sand and reported a significant decrease in the maximum bending moments, the shear forces and the displacements of the walls when the tyre aggregate was used as backfill. Shrestha and Ravichandran [21] investigated the static and dynamic behaviour of a retaining wall backfilled with tire shreds. They concluded that the shredded tire backfill significantly reduces maximum shear force and bending moment along the wall.

Generally, the existing codal provisions provide guidance through a traditional approach to verify the geotechnical and structural behaviour of cantilever walls [22-24]. They are based on the well-known the earth pressure theories and often underestimate the system strength due to conservative selection of soil strength parameters, including the effect of cohesion and wave propagation [25-27].

Very limited studies exist on the use of tyre shreds as compressible inclusion material between the wall and backfill. The objective of the present study is to evaluate the effect of the thickness of compressible inclusion consisting of tyre shreds on the behaviour of the cantilever retaining wall under cyclic harmonic motion. Numerical model developed using the finite element software PLAXIS v. 2017 was validated against the shaking table tests available in the literature.

Figure 1 shows a flowchart of the research methodology employed in this study.

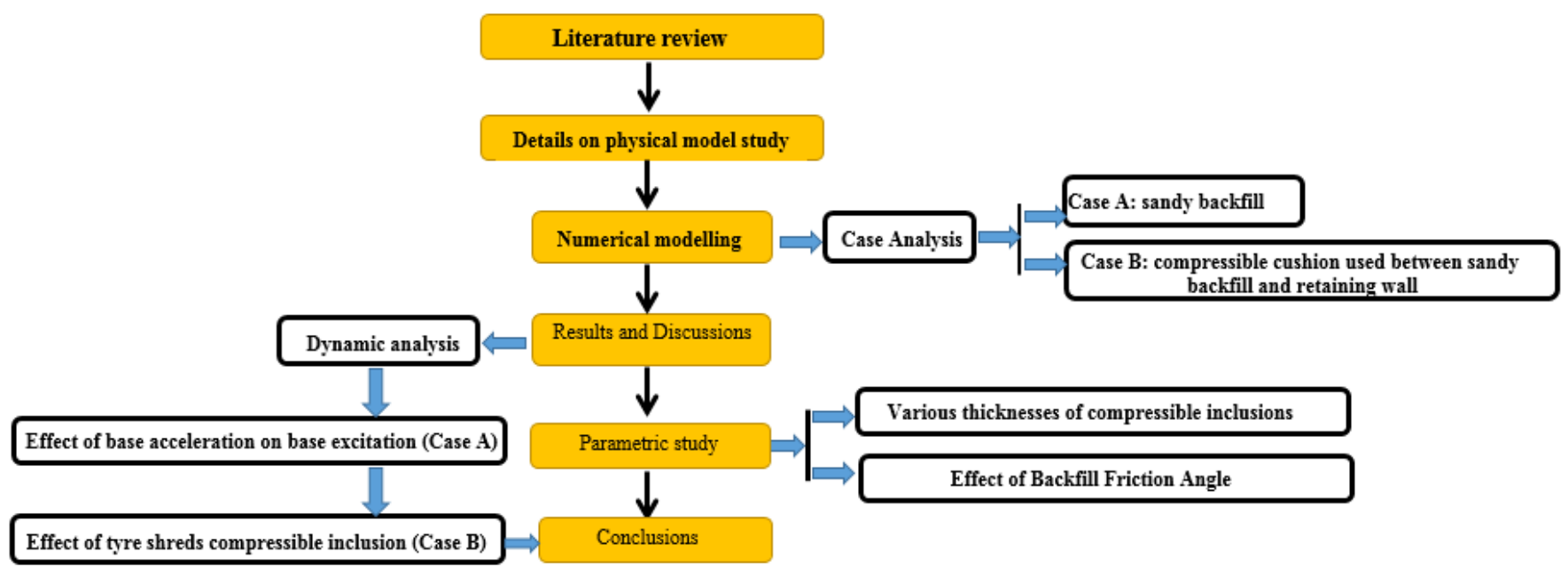

Figure 1. Research methodology flowchart 
This study was presented in the following sequence. First, the finite element model developed was verified by experimental findings of physical models [28], and the results were also compared and validated with results of published numerical studies. Then two series of analysis were carried out. In the first series (Case A), a retaining wall model with backfill soil was used (control case). In another series (Case B), tyre shreds were placed behind the wall in the form of compressible inclusions of three different thicknesses. The wall was subjected to sinusoidal motion excitation to determine the sensitivity of the targeted results (i.e., the permanent displacement and horizontal earth pressure) with regard to the variation of the principal parameters, namely different thicknesses of tyre shreds as a cushion and the friction angle of the granular material. All the results were discussed and conclusions were drawn at the end of the study.

\section{Development and Validation of Numerical Model}

\subsection{Details on Physical Model Study}

Physical model tests conducted in the container by Kloukinas et al. [28] were adopted as the reference case models for developing the numerical model. The target physical model wall was $4.8 \mathrm{~m}$ long $\times 1 \mathrm{~m}$ wide and $1.15 \mathrm{~m}$ deep, constructed in a flexible laminar container. The apparatus was kept on the shake table of aluminium of $3 \times 3 \mathrm{~m}$ size and a payload capacity of 3.8 tons were used in the tests. The shaking can be equipped with various frequencies from 1 $\mathrm{Hz}$ to $100 \mathrm{~Hz}$. The overall device is provided with 21 1-D accelerometers to determine accelerations, 4 LVDT (linear variable differential transducer) to capture dynamic response and permanent displacement, and 32 strain measures to observe the wall bending. Figure 2 shows the dimensions of the model and the position of instrumentation used in the experiment. The model comprised of L-shaped retaining walls with a $0.6 \mathrm{~m}$ deep backfill resting on a $0.4 \mathrm{~m}$ deep soil layer. Configuration 1 comprised of wall heel of $300 \mathrm{~mm}$ with $50 \mathrm{~mm}$ toe. In Configurations 2 and 3, the wall heel was shortened by $50 \mathrm{~mm}$ making it $250 \mathrm{~mm}$ in both cases and the toe was removed after increasing the frictional resistance of the base interface from $23.5^{\circ}$ to $28^{\circ}$, by gluing with a rough sandpaper. The interface friction angles were measured in-situ through static pull tests on the wall. The foundation layer and backfill were both made up of Leighton Buzzard (LB) sand (Fraction B) prepared at different compaction levels. Based on the relative densities, $D_{r}$, of sand prepared, the peak friction angles of the foundation layer and the backfill were estimated from empirical correlations as $42.5^{\circ}$ and $33.5^{\circ}$, proposed by the experimental work of Cavallaro et al. [29]. Figure 3 shows the overall sand layers specified in two different sections with different frequencies $\left(f_{l n}\right)$ and a shear modulus $\left(G_{0}\right)$. The retaining wall model was made of aluminium alloy 5083 plates of thickness $32 \mathrm{~mm}$ with properties: unit weight $\gamma=27 \mathrm{kN} / \mathrm{m}^{3}$, Young's modulus $E=$ $70 \mathrm{GPa}$ and Poisson's ratio $v=0.3$. The harmonic acceleration was loaded by a sinusoidal excitation composed of 15 stable cycles. An excitation frequency of $7 \mathrm{~Hz}$ was then chosen for a series of sinusoidal seismic excitations with increasing amplitude Kloukinas et al. [28].

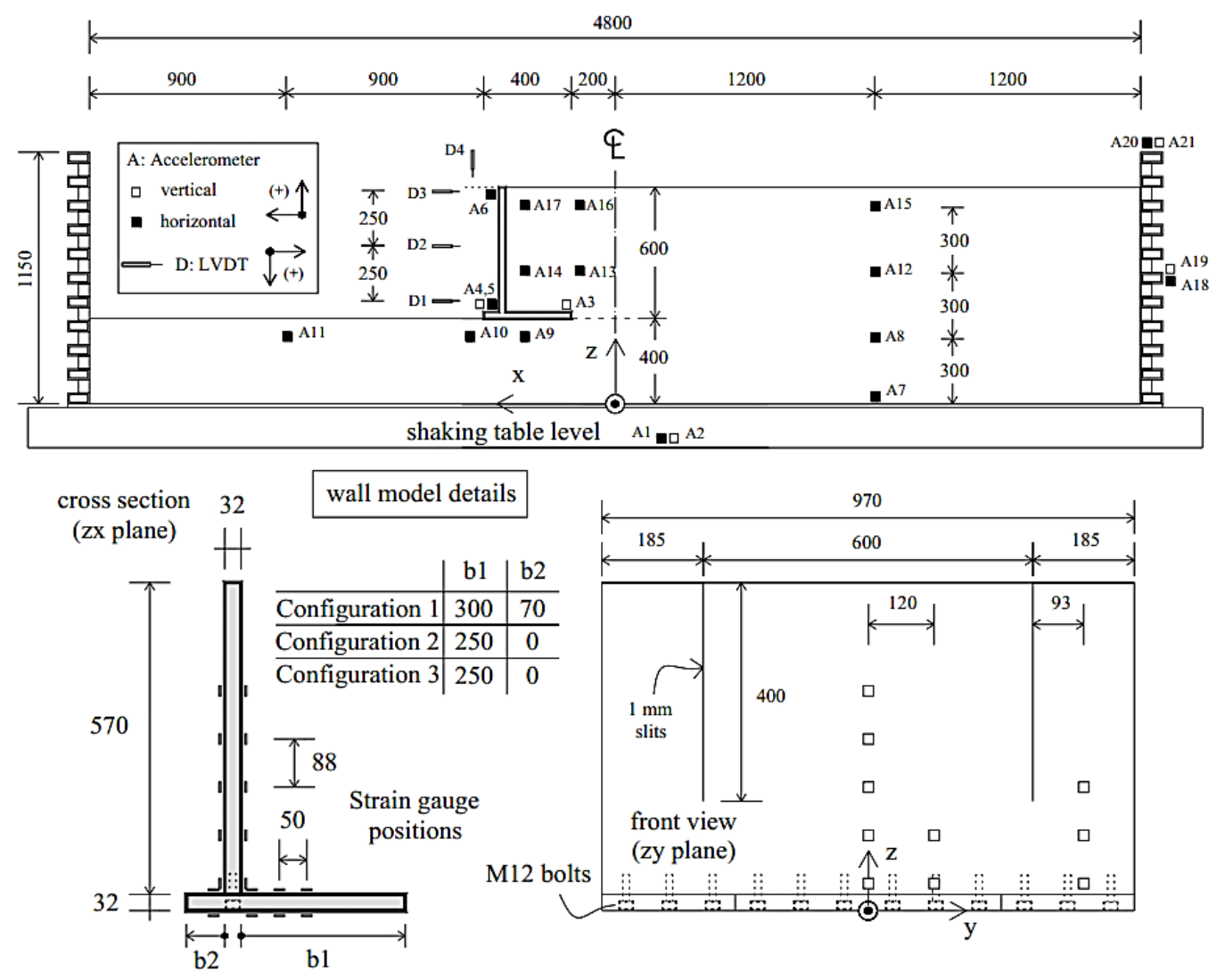

Figure 2. Geometry and instrumentation of shake test table [28] (dimensions in mm) 


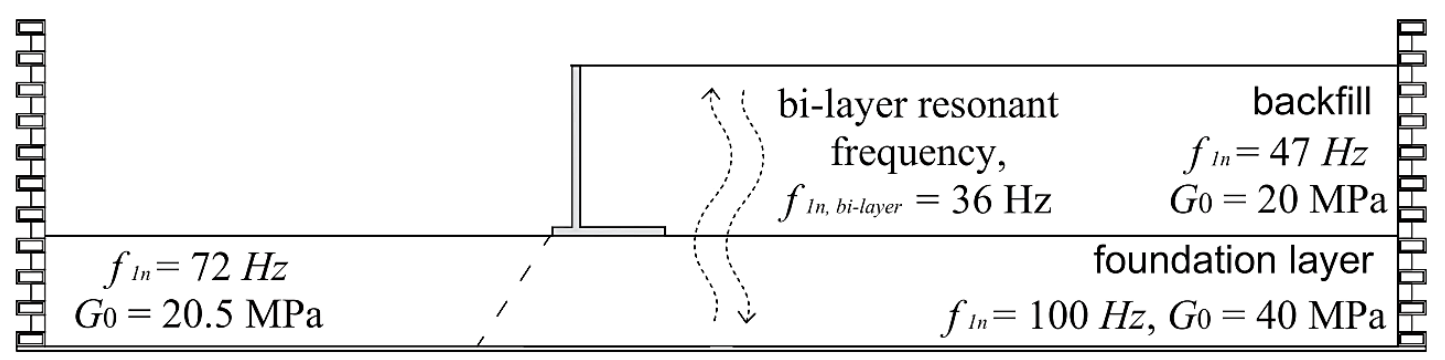

Figure 3. Frequencies and shear modulus for different sand layers [28]

\section{Numerical Modelling}

In this study, same size as the physical shaking table test model $4.8 \mathrm{~m}$ wide and $1 \mathrm{~m}$ high, was simulated numerically using PLAXIS 2D. The size of a retaining wall was taken for Configuration 3 with height of $600 \mathrm{~mm}$ and a base width of $250 \mathrm{~mm}$. Three node points D1, D2 and D3 along the height of the wall were taken to record the displacement histories of the wall (refer to Figure 4).

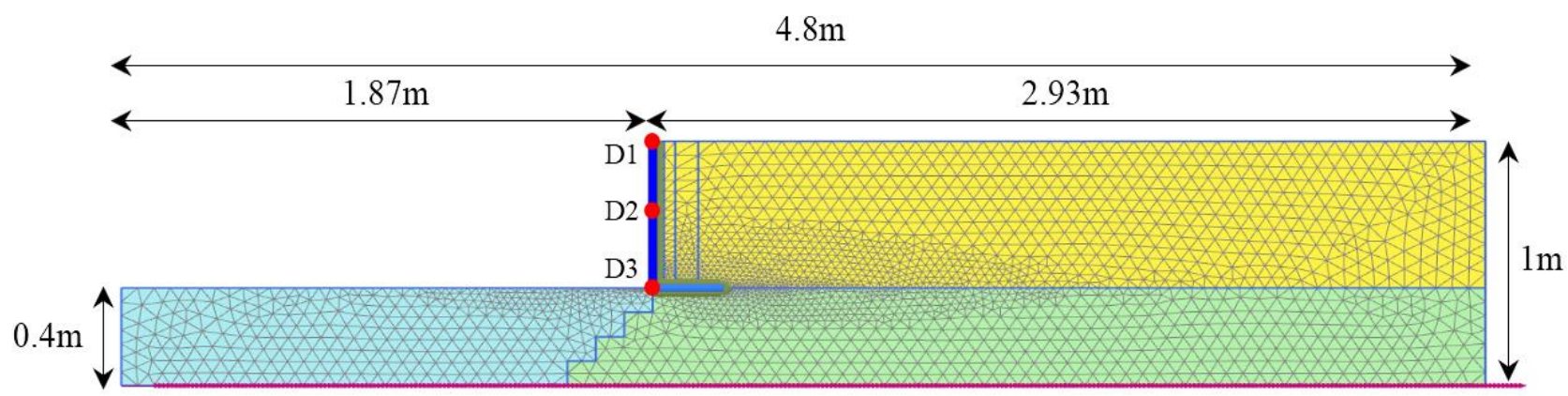

Figure 4. Finite element mesh used in the numerical model in PLAXIS for shake table test.

\subsection{Case Analysis}

Figure 5 shows the two series of analyses carried out in the study. In first series (Case A), a retaining wall model with a medium dense backfill was used (Control case). In another series (Case B), tyre shreds were placed vertically in the form of compressible inclusions with three different thicknesses, chosen as follow: $25 \mathrm{~mm}, 50 \mathrm{~mm}$ and $100 \mathrm{~mm}$ $(t / H=0 \cdot 04,0.08$ and $0 \cdot 16)$, behind the model wall as a buffer cushion, in which $t$ denotes thickness of tyre shreds and $H$ denotes the wall height. To better comprehend the behaviour of compressible inclusions under harmonic cyclic loading conditions, parametric studies were conducted on different models (as presented in Table 1), which expresses the dynamic response of each model in terms of the lateral earth pressures and displacements.

Table 1. Parameters of the different models for finite element analysis

\begin{tabular}{cccc}
\hline Thickness of compressible inclusion $(\boldsymbol{t})(\mathbf{m m})$ & Code $\boldsymbol{t} / \boldsymbol{H}$ & Input acceleration $(\mathbf{g})$ & Excitation \\
\hline 0.00 & 0.00 (Control Case) & 0.1 & \\
25 & 0.04 & 0.2 & \\
50 & 0.08 & 0.3 & Sinusoidal, $7 \mathrm{~Hz} 15$ cycles \\
100 & 0.16 & & \\
& Backfill $\phi\left(30,40^{\circ}\right)$ & & \\
0.00 & $0.00($ Control Case) & & \\
25 & 0.04 & & \\
50 & 0.08 & & \\
\hline
\end{tabular}


(a) Case A

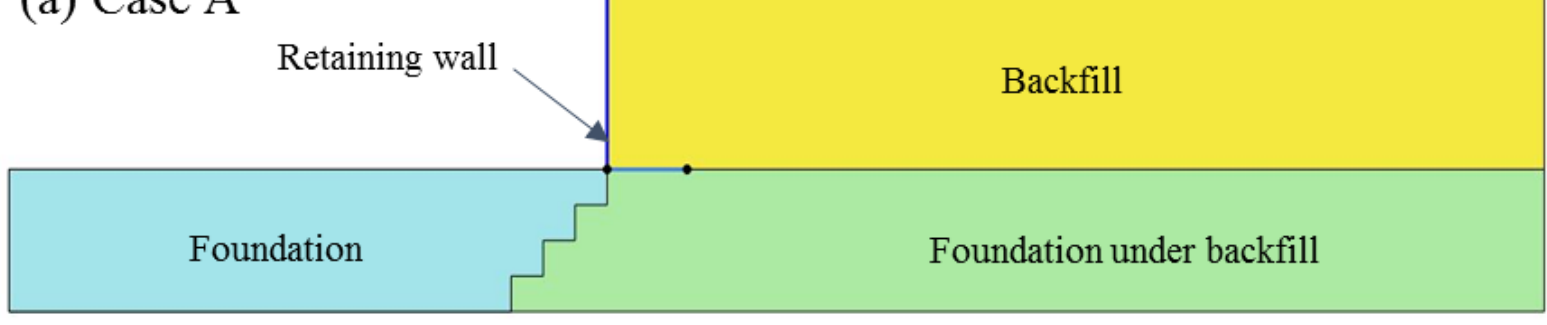

Tyre Shreds Cushion

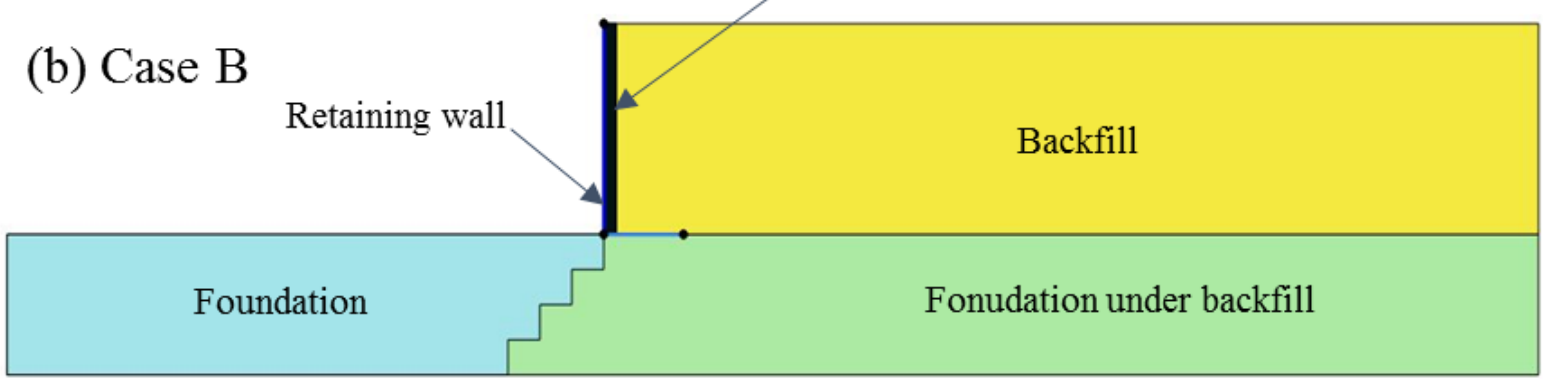

Figure 5. Model cases considered: (a) Case A: sandy backfill, and (b) Case B: compressible cushion used between sandy backfill and retaining wall

\subsection{Materials Models Used}

The numerical study was performed for 15 nodes elements and plane deformation condition. The material parameters for the sand and retaining wall have been taken similar to those from the shake table test. In this research, the Mohr-Coulomb elastoplastic model was used to illustrate the stress-strain behaviour of foundation, soil and backfill materials, especially when subjected to dynamic loads (see Table 2).

The tyre shreds material was modelled as a linear elasto-plastic material. The cushion layer consisted of pure tyre shreds (grain size 50-150 mm). The unit weight of the tyre shreds, friction angle, and cohesion were taken as 6.313 $\mathrm{kN} / \mathrm{m}^{3}, 23^{\circ}$, and $6.749 \mathrm{kN} / \mathrm{m}^{2}$, respectively. The tyre shreds properties obtained are shown in Table 2 , which are in the range of the results reported by Shrestha et al. [20].

Table 2. Material properties used in numerical simulations

\begin{tabular}{ccccccc}
\hline Material & $\gamma\left(\mathbf{k N} / \mathbf{m}^{3}\right)$ & $\boldsymbol{E}\left(\mathbf{k N} / \mathbf{m}^{2}\right)$ & $\boldsymbol{c}\left(\mathbf{k N} / \mathbf{m}^{2}\right)$ & $\phi\left({ }^{\circ}\right)$ & $\boldsymbol{v}$ & $\boldsymbol{R}_{\text {inter }}$ \\
\hline Foundation (dense sand) & 16.14 & $53.3 \times 103$ & 1 & 42 & 0.3 & 0.6 \\
Foundation (dense sand) under backfill & 16.14 & $104 \times 103$ & 1 & 42 & 0.3 & 0.6 \\
backfill (medium dense sand) & 15.11 & $52 \times 103$ & 1 & 34 & 0.3 & 0.6 \\
Tyre shreds & 6.313 & 1363 & 6.8 & 23 & 0.29 & 0.6 \\
\hline
\end{tabular}

\subsection{Properties of Structural Components}

The retaining wall was modelled as a linear-elastic material. In PLAXIS input, the properties of the wall are defined by its elastic stiffness $(E A)$, flexural rigidity $(E I)$, unit weight $(\gamma)$, Poisson ratio $(v)$ and its weight $(W)$. The properties utilised in the modelling are shown in Table 3.

Table 3. Material properties of the retaining wall

\begin{tabular}{cccc}
\hline Parameter & Symbol & Value & Unit \\
\hline Elastic stiffness & $E A$ & $2.24 \times 10^{6}$ & $(\mathrm{kN} / \mathrm{m})$ \\
Flexural rigidity & $E I$ & 191 & $\left(\mathrm{kN} / \mathrm{m}^{2} / \mathrm{m}\right)$ \\
Unit weight & $\gamma$ & 27 & $\left(\mathrm{kN} / \mathrm{m}^{3}\right)$ \\
Weight of wall & $W$ & 0.86 & $(\mathrm{kN} / \mathrm{m} / \mathrm{m})$ \\
Poisson ratio & $v$ & 0.3 & - \\
\hline
\end{tabular}




\subsection{Dynamic Analysis}

\subsubsection{Damping}

In PLAXIS, the dynamic calculations depend on the fundamental equation of the movement of a volume as a function of time under the influence of a dynamic load [30]. The relative damping of mass and stiffness is computed as given in Equation 1.

$$
C=\alpha_{R} M+\beta_{R} K
$$

Where $C, M$, and $K$ are the damping matrix, the mass matrix, and the stiffness matrix, respectively. $\alpha$ and $\beta$ are the Rayleigh coefficients. Given the Rayleigh damping, a relationship can be established between the damping ratio $\xi$ and Rayleigh damping parameters $\alpha$ and $\beta$ :

$$
\alpha_{R}+\beta_{R} \omega^{2}=2 \omega \xi \text {, with } \omega=2 \pi f
$$

In Equation 2, $\omega$ is the angular frequency $(\mathrm{rad} / \mathrm{s})$ and $\mathrm{f}$ the frequency $(\mathrm{Hz})$. Resolving Equation 2, for two different target frequencies and corresponding target damping ratios give the required Rayleigh damping coefficients:

$$
\begin{aligned}
& \alpha_{R}=2 \omega_{1} \omega_{2} \frac{\omega_{1} \xi_{2}-\omega_{2} \xi_{1}}{\omega_{1}^{2}-\omega_{2}^{2}} \\
& \beta_{R}=2 \frac{\omega_{1} \xi_{1}-\omega_{2} \xi_{2}}{\omega_{1}^{2}-\omega_{2}^{2}}
\end{aligned}
$$

In PLAXIS 2D, the target frequencies and damping ratios can be specified after the Rayleigh coefficients are automatically calculated through Equations 3 and 4, where $\xi$ is the target damping of $5.0 \%$. Hudson and Beirkae [31] and Hashash and Park [32] explain that the first target frequency can be taken as the first natural frequency $f_{1}$ and the second target frequency is taken as the closest odd integer larger than the ration $f_{p} / f_{1}$, the ratio of the predominant frequency of the input motion to the natural frequency of the soil. The natural frequency of soil deposition of thickness $H$ is related to its geometry and its stiffness by this equation:

$f_{1}=\frac{v_{s}}{4 H}$

Where, $v_{s}$ is the shear wave velocity in the soil deposition, a function of the shear stiffness modulus $G$. The values of the Raleigh damping coefficients and the dynamic soil properties were calculated using Equations 3 to 5 and are shown in Table 4.

Table 4. Rayleigh damping coefficients for backfill and foundation materials

\begin{tabular}{cccccc}
\hline Soil & $\boldsymbol{H}(\mathbf{m})$ & $\boldsymbol{V}_{\boldsymbol{s}}(\mathbf{m} / \mathbf{s})$ & $\boldsymbol{f}_{\boldsymbol{l}}(\mathbf{H z})$ & $\boldsymbol{\alpha}$ & $\boldsymbol{\beta}$ \\
\hline Foundation (dense sand) & 0.4 & 115.9 & 72.438 & 4.103 & 0.0001524 \\
Foundation (dense sand) under backfill & 0.4 & 111.6 & 69.750 & 3.997 & 0.0002074 \\
backfill (medium dense sand) & 0.6 & 113.8 & 47.416 & 3.832 & 0.0002925 \\
Tyre shreds & 0.6 & 28.65 & 11.937 & 2.772 & 0.0008404 \\
\hline
\end{tabular}

\subsubsection{Element Size}

For the finite element model, the size of the mesh elements discretizing the soil profile of the dynamic calculation is a major importance to ensure a correct propagation of the waves in the model. The maximum element size can be determined according to Kuhlemeyer and Lysmer [33]. In this theory, the maximum size of the elements in a layer is limited by the maximum frequency and the shear wave velocity of a layer as given in Equation 6:

$$
\text { Average Element size } \leq \frac{\lambda}{8}=\frac{V_{S, \min }}{8 \times f_{\max }}
$$

\subsubsection{Interface Properties}

In order to model the interaction between soil and structural units, it is necessary to identify interfaces. This is done to specify a lower resistance between a structured surface and the soil. Without interface elements, no slipping or gapping is allowed, which in most cases is a non-physical assumption for the interaction between structure and soil. Strength and stiffness reductions are introduced through the use of interfaces, by the parameter $R_{\text {inter }}$. The interface strength was reduced by using the strength reduction factor of $0.60<1$ in these analyses. 


\subsubsection{Boundary Conditions}

A standard absorbent boundary applied to the model as suggested in the user's manual [30] for dynamic analysis. The absorbent boundaries are applied at $\mathrm{x}$-min and $\mathrm{x}$-max of the model to absorb the increments of stress on the boundaries due to the dynamic loading and the base of the model domain against translation in both $\mathrm{x}$ and $\mathrm{y}$ directions. The fixed base has been applied with a horizontal prescribed displacement to the numerical model.

\subsubsection{Excitation}

The finite element model was subjected to a basic excitation representing a harmonic motion of variable amplitude. The frequency of the applied harmonic input base acceleration was the agent of a typical predominant frequency of medium-to-high frequency content earthquake as suggested by Bathurst and Hatami [34] and Matsuo et al. [35]. The constant frequency cyclic load was modelled by employing the prescribed displacement feature of the program at the base of the wall, as shown in Figure 4. The varied-amplitude harmonic excitation was chosen so that the gradual increase and then decrease in amplitude with a specified frequency makes this loading system similar to a genuine earthquake. The harmonic excitation is represented by Equation 9 and shown in Figure 6.

$$
a_{h}(t)= \begin{cases}\frac{a_{\max }}{5} f t \sin (2 \pi f t) & \left(t \prec \frac{5}{f}\right) \\ a_{\max } \sin (2 \pi f t) & \left(\frac{5}{f} \leq t \prec 3.357\right) \\ \frac{a_{\max }}{5}\left[\left(3.357+\frac{5}{f}-t\right)\right] f \sin (2 \pi f t) & \left(3.357 \leq t \leq 3.357+\frac{5}{f}\right)\end{cases}
$$

Where, $t$ is time, $f$ is the frequency, and $a_{\max }$ is the acceleration amplitude. The baseline model was subjected to a reference cyclic harmonic load with increasing amplitude of the input acceleration for a frequency of $7 \mathrm{~Hz}$ applied at equal time intervals of $5 \mathrm{~s}$, its accelerogram was obtained using Equation 9. The resulting acceleration time history was used as an input excitation in the numerical model.

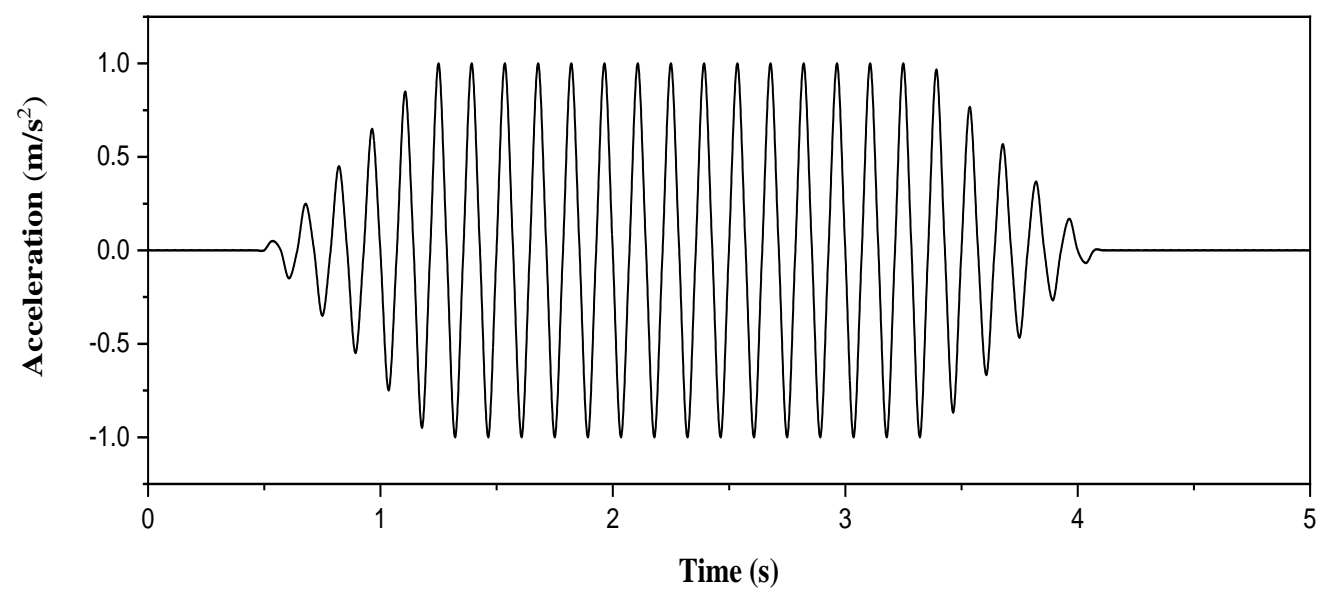

Figure 6. Input sinusoidal motion with $7 \mathrm{~Hz}$ frequency and amplitude $0.1 \mathrm{~g}$

\subsubsection{Fundamental Frequency of Analysed Walls}

Based on one and two-dimensional (2-D) elastic theory of vibration, the fundamental frequency of a linear-elastic media of width ' $B$ ' and height ' $H$ ' contained between two rigid vertical boundaries and a rigid base which is subjected to excite the horizontal base, is given by Bathurst and Hatami [34]:

$f=\frac{1}{4 H} \sqrt{\frac{G}{\rho}} \sqrt{1+\left(\frac{2}{1-v}\right)\left(\frac{H}{B}\right)^{2}}$

Where, $f$ is the frequency, $G$ is the shear modulus, $\rho$ is density and $v$ is the Poisson ratio of the soil medium. For the present model, the height of wall $H$ was $0.6 \mathrm{~m}$ and the width $B$ was $4.8 \mathrm{~m}$; considering soil density $(\rho)$ of $1.540 \mathrm{kN} / \mathrm{m}^{3}$, a shear modulus $(G)$ of $20,000 \mathrm{kN} / \mathrm{m}^{2}$ and a Poisson ratio $(v)$ of 0.3 , the fundamental frequency of the wall was calculated as $48.53 \mathrm{~Hz}$. This value is close to the frequency of the input harmonic acceleration recording $(f=7 \mathrm{~Hz})$ used in the numerical simulation. 


\section{Model Validation}

The comparison of the finite element analysis with the shake table tests was firstly done for the maximum dynamic wall displacement as a function of time, at the end of 15 cycles of harmonic excitation of $0.19 \mathrm{~g}$ and $0.23 \mathrm{~g}$ accelerations at $7 \mathrm{~Hz}$ frequency. Figure 7 shows the actual response in terms of the wall displacement time history from the shaking table test. D1, D2 and D3 represent the output points taken at the top, the middle and the bottom of the wall, respectively. The figure demonstrates an acceptable comparison between the results from the numerical and physical models to validate the numerical model in simulating the physical model shaking table tests on retaining walls.
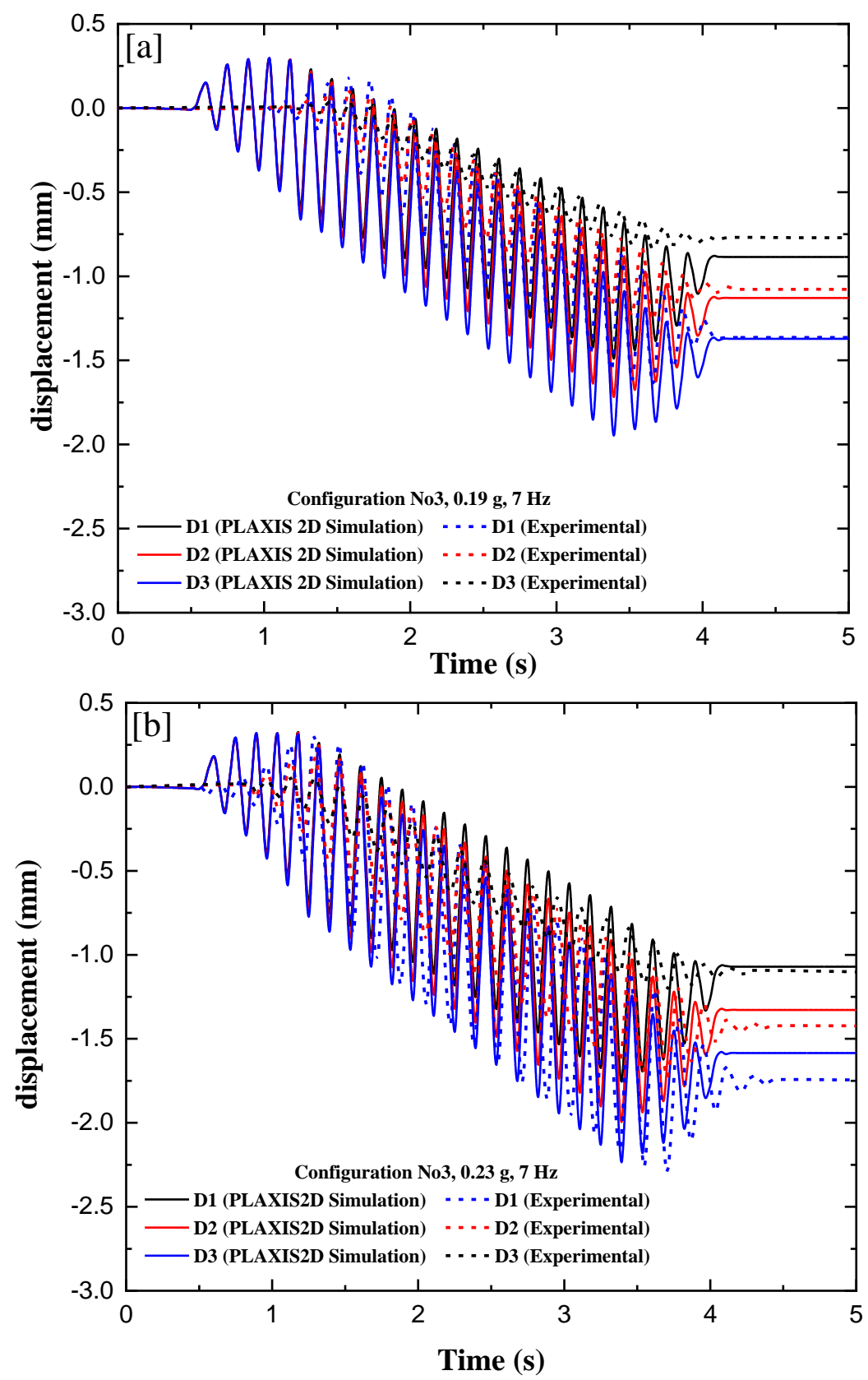

Figure 7. Comparison of results from numerical and physical model tests on Configuration $\mathrm{N}^{\circ} 3$ under sinusoidalharmonic excitation $(\mathrm{a}=\mathbf{0 . 1 9} \mathrm{g}, 0.23 \mathrm{~g}$, and $\mathrm{f}=7 \mathrm{~Hz}$ ): Horizontal displacement time-histories on the cantilever wall stem

\section{Results and Discussions}

The time histories of measured horizontal dynamics operating at different elevations for the wall during sinusoidal motion excitation for both model cases (Cases A and B) are compared with Figure 8. The displacements at D1, D2, and D3 correspond to the elevations of $50 \mathrm{~mm}, 300 \mathrm{~mm}$ and $550 \mathrm{~mm}$ from the base, respectively. It can be seen in the figure that the direction of the displacements increases non-linearly with the increase of a number of cycles. The maximum displacement recorded at the end of cycles to model without the cushion $(t / H=0)$ was about $3 \mathrm{~mm}, 2.41$ $\mathrm{mm}$ and $1.80 \mathrm{~mm}$ at elevations of $550 \mathrm{~mm}, 300 \mathrm{~mm}$ and $50 \mathrm{~mm}$, respectively. In the presence of compressible cushion $(t / H=0.16)$, the maximum displacements of about $1.36 \mathrm{~mm}, 1.31 \mathrm{~mm}$ and $1.26 \mathrm{~mm}$ were obtained at elevations of 550 
$\mathrm{mm}, 300 \mathrm{~mm}$ and $50 \mathrm{~mm}$, respectively. At the end of the simulation time, it was found that the wall reinforced with tyre shreds had lower displacements in the horizontal direction as compared to the control case without the cushion.
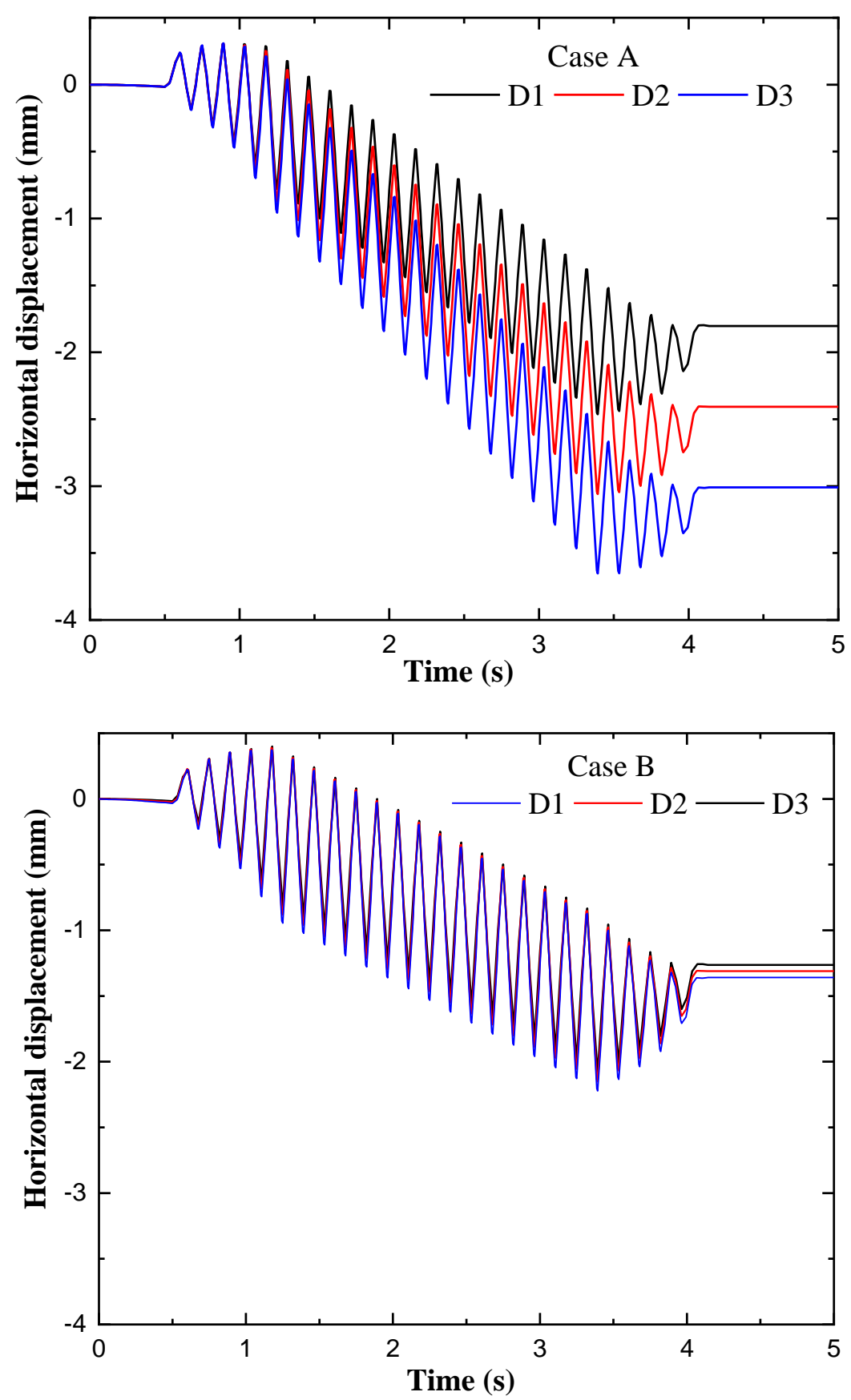

Figure 8. Time histories of horizontal displacements at different elevations for Cases A and B after 15 cycles of $0.3 \mathrm{~g}$ at $7 \mathrm{~Hz}$ dynamic motion

\subsection{Effect of Base Acceleration on Base Excitation (Case A)}

The model wall subjected to end of 15 cycles of sinusoidal motion excitation with accelerations of $0.1 \mathrm{~g}, 0.2 \mathrm{~g}$ and $0.3 \mathrm{~g}$ at a frequency of $7 \mathrm{~Hz}$ was considered to examine its influence on the performance of retaining walls. Figure 9(a) shows the influence of base acceleration on the permanent displacement response of the wall without the cushion $(t / H$ $=0$ ). The maximum displacements were observed at the top of the wall in all simulations. The maximum displacements were equal to $0.84 \mathrm{~mm}, 1.54 \mathrm{~mm}$ and $3.08 \mathrm{~mm}$ at input acceleration for $0.1,0.2$ and $0.3 \mathrm{~g}$ base acceleration, respectively. Figure 9(b) shows that the horizontal earth pressures are seen at the end of dynamic excitation with the height of the wall in different models. It can be seen that horizontal earth pressure showed an increasing trend for the control case $(t / H=0)$ with an increase in the base acceleration of $0.1 \mathrm{~g}, 0.2 \mathrm{~g}$, and $0.3 \mathrm{~g}$, respectively. However, it was observed that the peak horizontal earth pressures occur at the bottom in the model wall. 

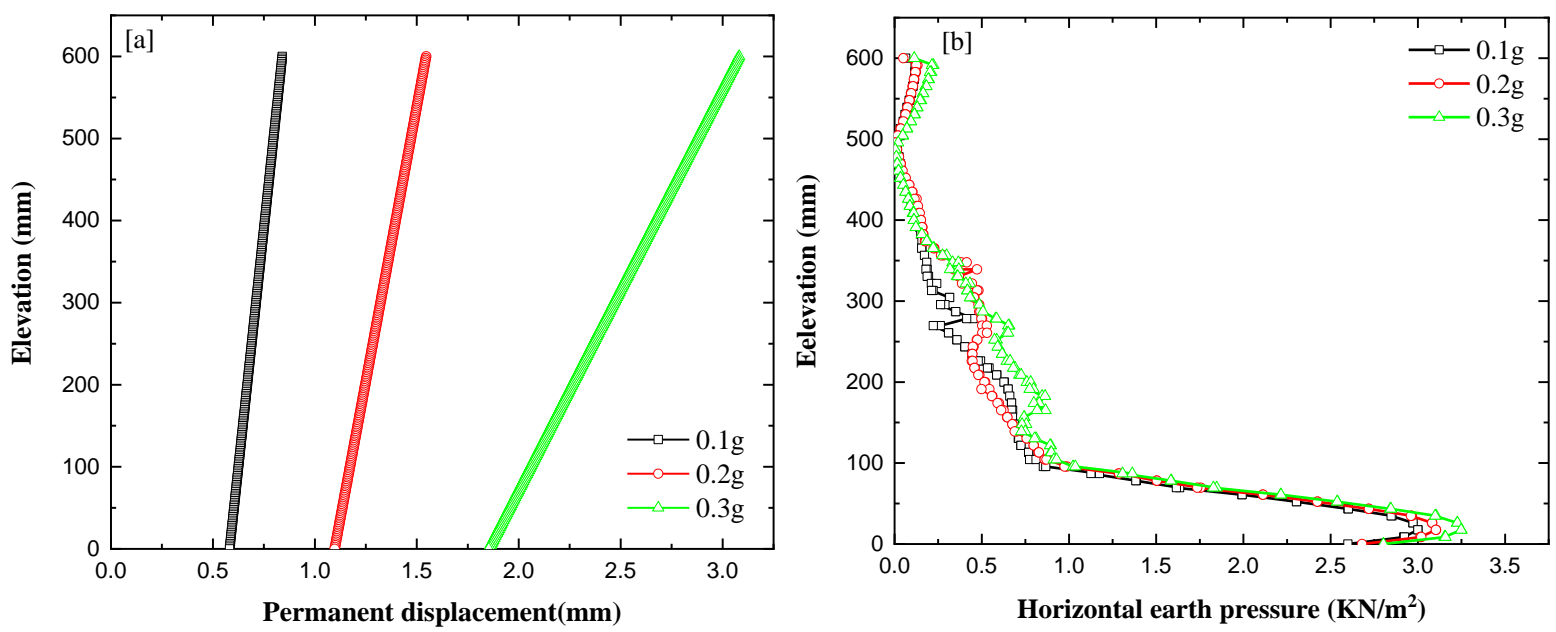

Figure 9. Response of the walls under different harmonic loads for control case: (a) Permanent displacement, and (b) Horizontal earth pressure

\subsection{Effect of Tyre Shreds Compressible Inclusion (Case B)}

To study the effects of compressible inclusion, thickness on the model wall response is examined by employing different input base motions. The responses of the model wall with various compressible inclusion thicknesses were compared to those of the controlled case $(t / H=0)$ model wall at similar excitation levels.

Figure 10 (a) shows the displacement wall that was excited with a sinusoidal motion of $0.1 \mathrm{~g}$ acceleration and $7 \mathrm{~Hz}$ frequency, at the end of 15 cycles, showing the influence of compressible inclusion on the permanent displacement response. It can be seen that the permanent displacements are significantly reduced with the increase in the thickness of the compressible inclusions just behind the retaining wall. The maximum displacement of 0.84 mm with the model $t / H=0$ was reduced to $0.69 \mathrm{~mm}, 0.59 \mathrm{~mm}$ and $0.49 \mathrm{~mm}$ for models using $t / H=0.04,0.08$ and 0.16 , respectively. A reduction of $16.9 \%, 28.9 \%$ and $40.9 \%$ in the permanent displacements as compared to control case $(t / H=0)$ were obtained. Figure 10 (b) shows that the horizontal earth pressures decreased with an increase of compressible inclusion thickness along wall height for $t / H$ ratios of $0.04,0.8$ and 0.16 models $(a=0.1 \mathrm{~g}$ and $f=7 \mathrm{~Hz}$ ). The maximum horizontal earth pressure $3 \mathrm{kN} / \mathrm{m}^{2}$ is noticed for the model $t / H=0$ and the corresponding values for the models $t / H=$ $0.04,0.8$ and 0.16 are $1.4 \mathrm{kN} / \mathrm{m}^{2}, 1.11 \mathrm{kN} / \mathrm{m}^{2}$ and $0.70 \mathrm{kN} / \mathrm{m}^{2}$, respectively. A reduction of about $52.9 \%$ to $76.5 \%$ in earth pressure compared to the control case $(t / H=0)$ were observed.
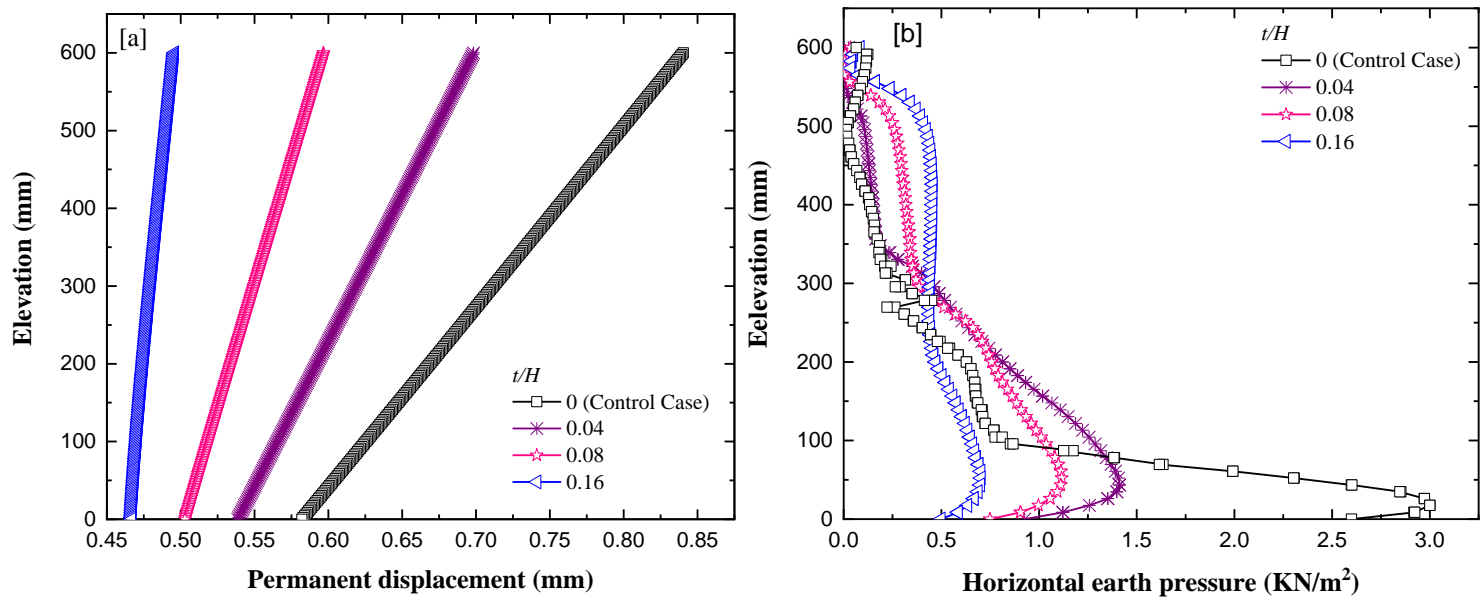

Figure 10. Effect of compressible inclusion thickness under sinusoidal-harmonic excitation of $0.1 \mathrm{~g}$ at $7 \mathrm{~Hz}$ : (a) Permanent displacement, and (b) Horizontal earth pressure

Figure 11 (a) shows the base acceleration (a) of $0.2 \mathrm{~g}$, dynamic motion is applied to the model wall at frequency $f=$ $7 \mathrm{~Hz}$. The maximum values of the permanent displacements were recorded for $t / H$ ratios of $0.04,0.8$ and 0.16 at the end of 15 cycles. The model results were $1.19 \mathrm{~mm}, 1.04 \mathrm{~mm}$ and $0.94 \mathrm{~mm}$ indicating a reduction of $22.44 \%, 32.1 \%$ and $38.9 \%$, respectively, compared to the control case $(t / H=0)$ with a displacement of $1.54 \mathrm{~mm}$. In Figure 11 (b), it was observed that horizontal earth pressures exhibit a decreasing trend with an increase in compressible inclusion thicknesses (i..e, $t / H$ ratios of $0.04,0.8$ and 0.16 ). The maximum earth pressures are observed in the model results were 
$1.66 \mathrm{kN} / \mathrm{m}^{2}, 1.29 \mathrm{kN} / \mathrm{m}^{2}$ and $0.88 \mathrm{kN} / \mathrm{m}^{2}$ which corresponds to a reduction of $46.4 \%, 58.2 \%$ and $71.6 \%$, respectively, compared with the model control case with $3.10 \mathrm{kN} / \mathrm{m}^{2}$ corresponding to $0.2 \mathrm{~g}$ acceleration and $3 \mathrm{~Hz}$ frequency of base motion.
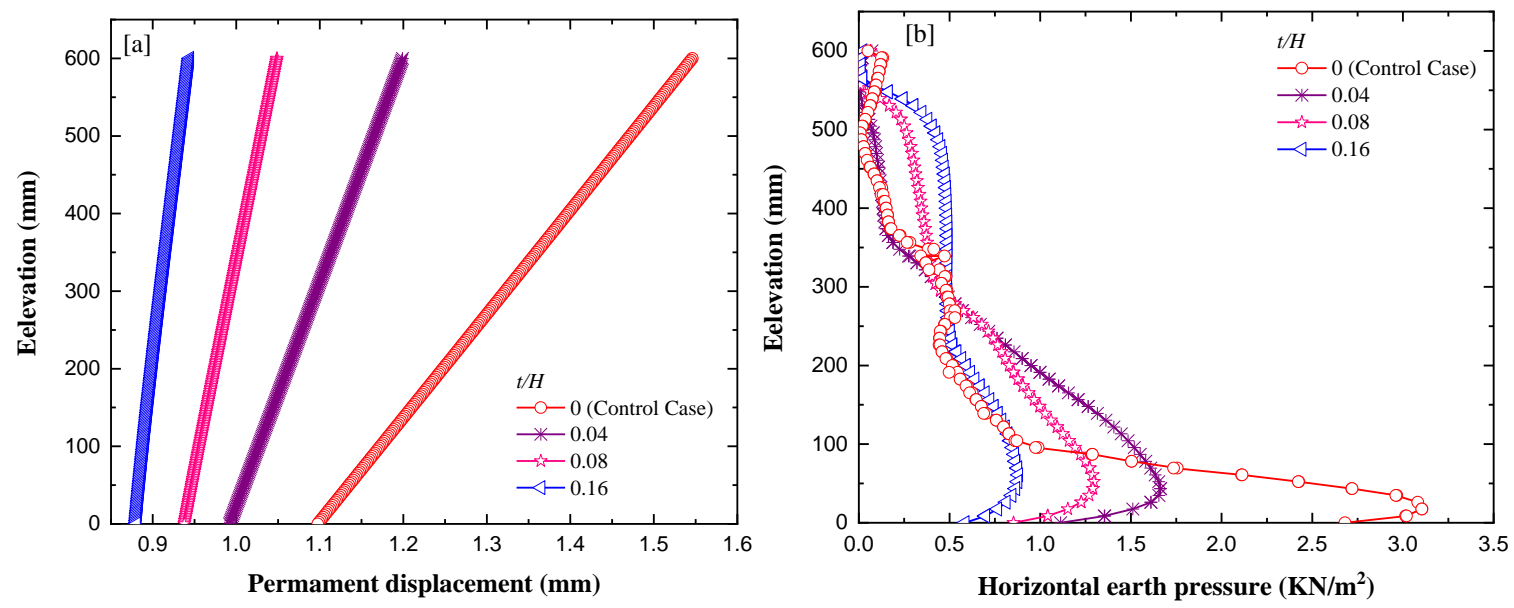

Figure 11. Effect of compressible inclusion thickness under sinusoidal-harmonic excitation of $0.2 \mathrm{~g}$ at $7 \mathrm{~Hz}$ : (a) Permanent displacement, and (b) Horizontal earth pressure

Figure 12 shows the effect of compressible inclusions on the model response in terms of permanent displacements and horizontal earth pressures. The base accelerations of $0.3 \mathrm{~g}$ and $7 \mathrm{~Hz}$ frequency have been applied on different model walls. As predicted, it is seen that the responses for $0.3 \mathrm{~g}$ acceleration are higher than of $0.2 \mathrm{~g}$ and $0.1 \mathrm{~g}$ acceleration excitation responses. From Figure 12(a), maximum values of the permanent displacement of $3.08 \mathrm{~mm}$ for the control case and the corresponding values for $t / H=0.04,0.8$ and 0.16 models are $2.51 \mathrm{~mm}, 2.02 \mathrm{~mm}$ and $1.55 \mathrm{~mm}$, respectively. A $49 \%$ reduction in the permanent displacements as compared with the control case $(t / H=0)$. Figure 12(b) shows the cushion material effectively reduces the dynamic horizontal earth pressures acting on the wall. The horizontal earth pressures of $3.25 \mathrm{kN} / \mathrm{m}^{2}$ is observed for model $t / H=0$ and the corresponding values for models using $t / H=0.04,0.08$ and 0.16 are $42.1 \%, 47.2 \%$ and $62.0 \%$, respectively.
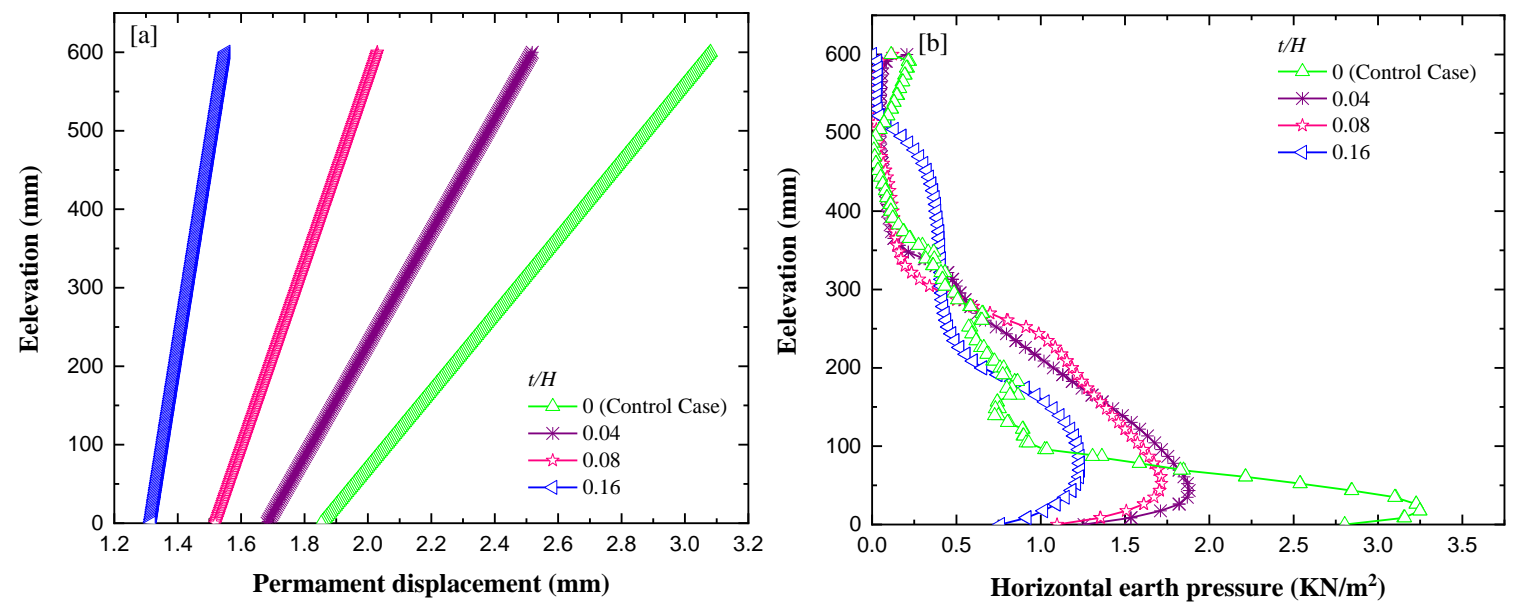

Figure 12. Effect of compressible inclusion thickness under sinusoidal-harmonic excitation of $0.3 \mathrm{~g}$ at $7 \mathrm{~Hz}:$ (a) Permanent displacement, and (b) Horizontal earth pressure

\subsection{Effect of Backfill Friction Angle}

To find the effect of friction angle of backfill soil on the harmonic response from retaining wall, dynamic horizontal earth pressure and permanent displacement of the retaining wall were tested for different friction angles of the backfill soil. It is possible to have backfill materials with possibly higher or lower friction angle than $34^{\circ}$, a parametric study was carried out considering the friction angles of $30^{\circ}$ and $40^{\circ}$. The dynamic response of the retaining wall model with two different backfill friction angles of $30^{\circ}$ and $40^{\circ}$ were considered. The comparative results after harmonic excitation ( $a=0.3 \mathrm{~g}, f=7 \mathrm{~Hz}$ ) for $t / H=0$ cases (no inclusion). The effect of friction angle on the response of model walls without the cushion $(t / H=0)$ is shown in Figure 13. Figure 13(a) presents the maximum horizontal at the wall top of $3.5 \mathrm{~mm}$ and $2.68 \mathrm{~mm}$ with backfill friction angles of $30^{\circ}$ and $40^{\circ}$, respectively. The permanent displacements decrease with an increase in friction angles of the backfill soil. Figure 13(b) shows that the horizontal earth pressures have no appreciable variation in the wall corresponding to different friction angles of the backfill at the end of dynamic 
excitation. However, the horizontal earth pressures in the model without the cushion of $3.37 \mathrm{kN} / \mathrm{m}^{2}$ and $2.99 \mathrm{kN} / \mathrm{m}^{2}$ with backfill friction angles of $30^{\circ}$ and $40^{\circ}$, respectively.
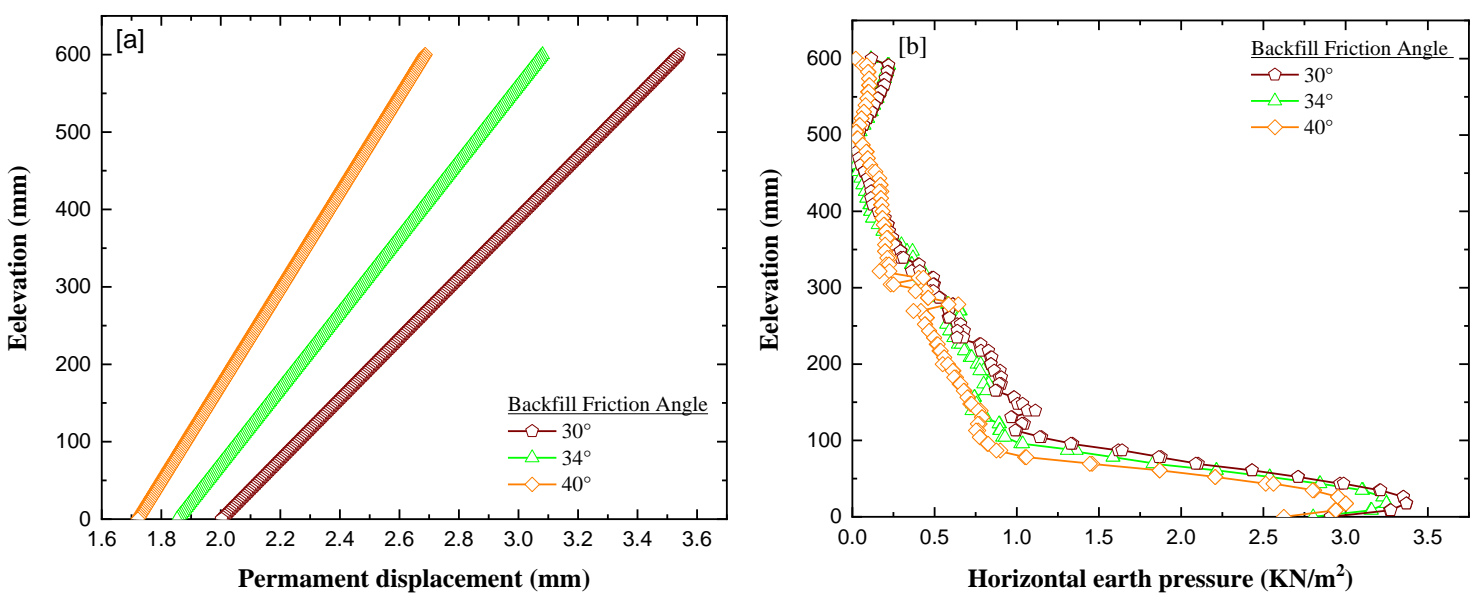

Figure 13. Response of the walls with backfill friction angles $30^{\circ}$ and $40^{\circ}$ subjected to dynamic excitation $(a=0.3 \mathrm{~g}, f=$ $7 \mathrm{~Hz}$ ) for control models: (a) Permanent displacement, and (b) Horizontal earth pressure

To evaluate the effects of the cushion, various thicknesses of compressible inclusions were used to analyse the effect of soil friction angle on the dynamic response is compared to the control case. As expected, an increase in the backfill soil friction angle increased the resistance of the soil. Figure 14(a) shows that the maximum displacements in the case of backfill friction angles of $30^{\circ}$ and $40^{\circ}$ for models with $t / H=0.16$ are 1.67 and 1.45 , indicating a reduction of 52.8\% and $45.9 \%$, respectively, compared to the control case $(t / H=0)$. As shown in Figure $10(\mathrm{~b})$, the lateral earth pressures are reduced with increased thickness $(t / H)$ of tyre shreds cushion with different backfill friction angles of $30^{\circ}$ and $40^{\circ}$. A reduction of approximately $55.8 \%$ to $65.7 \%$, respectively, in earth pressures for the model $t / H=0.16$ compared to the control case $(t / H=0)$ is observed. However, maximum displacements and earth pressures are decreased with an increasing thickness $(t / H)$ of tyre shreds cushion despite a change in the various friction angles of the backfill soil.
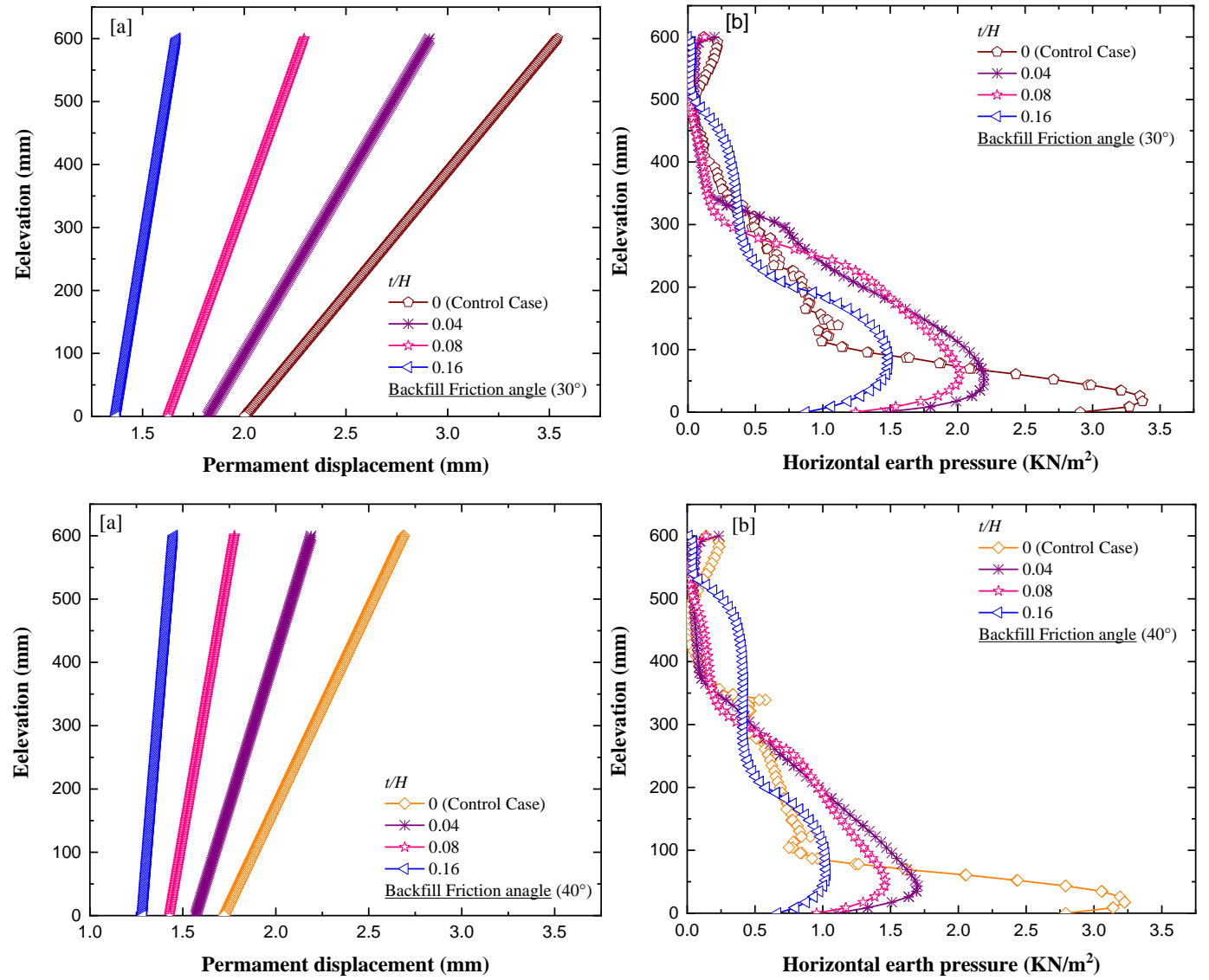

Figure 14. Response of the walls with backfill friction angles $30^{\circ}$ and $40^{\circ}$ subjected to dynamic excitation $(a=0.3 \mathrm{~g}, f=7 \mathrm{~Hz})$ for compressible inclusion: (a) Permanent displacement, and (b) Horizontal earth pressure 
Table 5. Comparison of maximum responses displacement, horizontal earth pressure and the percentage reduction

\begin{tabular}{|c|c|c|c|c|c|c|c|}
\hline \multirow[t]{2}{*}{ Input excitation } & \multicolumn{4}{|c|}{ Maximum displacements, $\mathbf{m m}$} & \multicolumn{3}{|c|}{ Percentage reduction } \\
\hline & $t=0 \mathbf{m m}$ & $t=25 \mathrm{~mm}$ & $t=50 \mathrm{~mm}$ & $t=100 \mathrm{~mm}$ & $t=25 \mathrm{~mm}$ & $t=50 \mathrm{~mm}$ & $\mathrm{t}=\mathbf{1 0 0} \mathbf{m m}$ \\
\hline $0.1 \mathrm{~g} \_7 \mathrm{~Hz}$ & 0.84 & 0.69 & 0.59 & 0.49 & 16.90 & 28.9 & 40.9 \\
\hline $0.2 \mathrm{~g} \_7 \mathrm{~Hz}$ & 1.54 & 1.19 & 1.04 & 0.94 & 22.44 & 32.1 & 38.9 \\
\hline $0.3 \mathrm{~g} \_7 \mathrm{~Hz}$ & 3.08 & 2.51 & 2.02 & 1.55 & 18.2 & 34.1 & 49.6 \\
\hline $\begin{array}{c}\text { Backfill }\left(\phi=30^{\circ}\right) \\
0.3 \mathrm{~g}_{-} 7 \mathrm{~Hz}\end{array}$ & 3.53 & 2.91 & 2.29 & 1.66 & 17.7 & 35.1 & 52.8 \\
\hline $\begin{array}{c}\text { Backfill }\left(\phi=40^{\circ}\right) \\
0.3 \mathrm{~g}_{-} 7 \mathrm{~Hz}\end{array}$ & 2.68 & 2.18 & 1.77 & 1.45 & 18.5 & 33.8 & 45.9 \\
\hline \multirow[t]{2}{*}{ Input excitation } & \multicolumn{4}{|c|}{ Maximum earth pressures, $\mathrm{kN} / \mathrm{m}^{2}$} & \multicolumn{3}{|c|}{ Percentage reduction } \\
\hline & $t=0 \mathbf{~ m m}$ & $t=25 \mathrm{~mm}$ & $t=50 \mathrm{~mm}$ & $t=100 \mathrm{~mm}$ & $t=25 \mathrm{~mm}$ & $t=50 \mathbf{~ m m}$ & $t=100 \mathrm{~mm}$ \\
\hline $0.1 \mathrm{~g} \_7 \mathrm{~Hz}$ & 3 & 1.41 & 1.11 & 0.70 & 52.9 & 62.8 & 76.5 \\
\hline $0.2 \mathrm{~g} \_7 \mathrm{~Hz}$ & 3.10 & 1.66 & 1.29 & 0.88 & 46.4 & 58.2 & 71.6 \\
\hline $0.3 \mathrm{~g} \_7 \mathrm{~Hz}$ & 3.25 & 1.87 & 1.71 & 1.23 & 42.1 & 47.2 & 62.0 \\
\hline $\begin{array}{c}\text { Backfill }\left(\phi=30^{\circ}\right) \\
0.3 \mathrm{~g}_{-} 7 \mathrm{~Hz}\end{array}$ & 3.37 & 2.19 & 2.01 & 1.48 & 34.8 & 40.2 & 55.8 \\
\hline $\begin{array}{c}\text { Backfill }\left(\phi=40^{\circ}\right) \\
0.3 \mathrm{~g}_{-} 7 \mathrm{~Hz}\end{array}$ & 2.99 & 1.69 & 1.46 & 1.02 & 43.3 & 51.3 & 65.7 \\
\hline
\end{tabular}

The results presented above indicate that recycled tyre shreds acted well as compressible inclusions in reducing permanent displacements and horizontal earth pressures on the wall, of the three various thicknesses, considered the lowering is larger in the thicker compressible layer due to the lightweight and compressible nature of the tyre shreds. Its absorbance characteristic can also be considered as additional damping. The calculated maximum values of the permanent displacements, horizontal earth pressures, and percentage reduction were summarized up in Table 5. From the table, it can be concluded that the permanent displacements were reduced in the range of $38 \%$ to $52 \%$ and horizontal earth pressures were reduced by about $55 \%$ to $76 \%$.

\section{Conclusions}

In this study, a series of numerical simulations are performed using a PLAXIS model to determine the influence of the tyre shreds cushion thickness on dynamic performance of cantilever retaining walls. The calibrated numerical models were used to analyze the cantilever retaining walls with a compressible inclusion of waste tire shreds placed behind the retaining wall. Results were presented and discussed in terms of horizontal displacements of and earth pressures on the wall. The following conclusions were drawn from the study.

- The horizontal displacements and earth pressures are low when compressible tire shreds as a cushion was provided behind the wall.

- The horizontal displacements and earth pressures were decreased with an increase in the thickness of cushion made up of compressible tire shreds. The maximum permanent displacements of the model wall with compressible inclusion were reduced by approximately $49 \%$. The horizontal earth pressures were reduced by up to $76 \%$ compared to the control case.

- The numerical model was used to quantify the effects of friction angle on the dynamic response in terms of the horizontal displacements and earth pressures and showed much superior performance to that of a granular backfill.

- The parametric study of the friction angle variation of the granular backfill material showed that a decrease in friction angle a more positive effect on performing compressible inclusions. It was revealed that $45 \%$ to $52 \%$ reduction in maximum values of permanent displacements, and horizontal earth pressures were reduced by about $55 \%$ to $6 \%$.

Overall, the study indicates that increasing cushion thickness has a favorable effect on the dynamic behaviour of walls with the use of recycled tyre shreds as a compressible inclusion material. The results presented in this study concluded that there are distinct advantages in using waste tire shreds for retaining structures, especially in seismically active areas. However, it provides a useful indication for designers to improve both the economy and performance of this durable material despite the low cost of this material. The application of the proposed technique is also expected to be a great boon towards a sustainable environment. However, extensive numerical and full-scale studies are needed to investigate the response of scrap tyre derived recycled product (such as tyre chips and tyre shreds) in retaining walls applications when subjected to ground motions representing a range of earthquake records with a variety of structural components. 


\section{Acknowledgements}

The first author gratefully acknowledges the Algerian Ministry of Higher Education and Scientific Research for funding his Ph.D. program. He also thanks the Indian Institute of Technology Hyderabad for co-hosting his Ph.D. research work.

\section{Funding}

Funding by the Ministry of Higher Education and Scientific Research in Algeria.

\section{Conflicts of Interest}

The authors declare no conflict of interest.

\section{References}

[1] Humphrey, DN., T Cosgrove, NL Whetten, and R Hebert. "Tire Chips Reduce Lateral Earth Pressure against the Walls of a Rigid Frame Bridge": Proceeding of the Conference on Renewal, Rehabilitation and Upgrades in Civil and Environmental Engineering." Paper presented at the 1997 Maine Section ASCE Technical Seminar, 1997.

[2] Hazarika, Hemanta, Eiji Kohama, and Takahiro Sugano. "Underwater Shake Table Tests on Waterfront Structures Protected with Tire Chips Cushion.” Journal of Geotechnical and Geoenvironmental Engineering 134, no. 12 (December 2008): 17061719. doi:10.1061/(asce)1090-0241(2008)134:12(1706).

[3] Reddy., Sodom Bali, and Adapa Murali Krishna. "Tyre Chips as Compressible Inclusions in Earth-Retaining Walls." Proceedings of the Institution of Civil Engineers-Ground Improvement 170, no. 3 (August 2017): 137-148. doi:10.1680/jgrim.16.00034.

[4] Balunaini, Umashankar, Sungmin Yoon, and Monica Prezzi. "Tire Shred Backfill in Mechanically Stabilized Earth Wall Applications" (2009). doi:10.5703/1288284314319.

[5] Akbarimehr, Davood, and Esmael Aflaki. “An Experimental Study on the Effect of Tire Powder on the Geotechnical Properties of Clay Soils.” Civil Engineering Journal 4, no. 3 (April 7, 2018): 594. doi:10.28991/cej-0309118.

[6] Akbarimehr, Davood, Esmail Aflaki, and Abolfazl Eslami. "Experimental Investigation of the Densification Properties of Clay Soil Mixes with Tire Waste.” Civil Engineering Journal 5, no. 2 (February 26, 2019): 363. doi:10.28991/cej-2019-03091251.

[7] Humphrey, Dana N, and William P Manion. "Properties of Tire Chips for Lightweight Fill." Paper presented at the Grouting, soil improvement and geosynthetics, (1992): 1344-1355.

[8] Edil, T. B, and Bosscher, P. J. "Development of Engineering Criteria for Shredded Waste Tires in Highway Applications. Final Report." 1992: 453-464

[9] Ahmed, Imtiaz, and CW Lovell. "Rubber Soils as Lightweight Geomaterials." Transportation research record, no. 1422 (1993).

[10] Cecich, V. "Use of Shredded Tires as Lightweight Backfill Material for Retaining Structures." Waste Management \& Research 14, no. 5 (October 1996): 433-451. doi:10.1006/wmre.1996.0043.

[11] Foose, Gary J., Craig H. Benson, and Peter J. Bosscher. "Sand Reinforced with Shredded Waste Tires." Journal of Geotechnical Engineering 122, no. 9 (September 1996): 760-767. doi:10.1061/(asce)0733-9410(1996)122:9(760).

[12] Tweedie, Jeffrey J, Dana N Humphrey, Thomas C Sandford, and New England Transportation Consortium. "Tire Chips as Lightweight Backfill for Retaining Walls-Phase II.” New England Transportation Consortium, (1998).

[13] Xiao, Ming, Jan Bowen, Mathew Graham, and Jesus Larralde. "Comparison of Seismic Responses of Geosynthetically Reinforced Walls with Tire-Derived Aggregates and Granular Backfills.” Journal of Materials in Civil Engineering 24, no. 11 (November 2012): 1368-1377. doi:10.1061/(asce)mt.1943-5533.0000514.

[14] Ahn, Il-Sang, and Lijuan Cheng. "Tire Derived Aggregate for Retaining Wall Backfill Under Earthquake Loading." Construction and Building Materials 57 (April 2014): 105-116. doi:10.1016/j.conbuildmat.2014.01.091.

[15] Reddy, S. Bali, and A. Murali Krishna. "Recycled Tire Chips Mixed with Sand as Lightweight Backfill Material in Retaining Wall Applications: An Experimental Investigation.” International Journal of Geosynthetics and Ground Engineering 1, no. 4 (October 23, 2015). doi:10.1007/s40891-015-0036-0.

[16] Dammala, Pradeep K., Bali R. Sodom, and Murali K. Adapa. "Experimental Investigation of Applicability of Sand Tire Chip Mixtures as Retaining Wall Backfill.” IFCEE 2015 (March 17, 2015). doi:10.1061/9780784479087.128.

[17] Reddy, S. Bali, and A. Murali Krishna. "Sand-scrap Tyre Chip Mixtures for Improving the Dynamic Behaviour of Retaining Walls.” International Journal of Geotechnical Engineering (August 7, 2019): 1-13. doi:10.1080/19386362.2019.1652969. 
[18] Lee, H.J, and Han S.R. "The Use of Recycled Tire Chips to Minimize Dynamic Earth Pressure During Compaction of Backfill.” Construction and Building Materials 21, no. 5 (May 2007): 1016-1026. doi:10.1016/j.conbuildmat.2006.02.003.

[19] Ravichandran, N, and Huggins, L. "Applicability of Shredded Tire Chips as a Lightweight Retaining Wall Backfill in Seismic Regions.” Geo-Congress 2014 Technical Papers (February 24, 2014). doi:10.1061/9780784413272.339.

[20] Shrestha, S., N. Ravichandran, M. Raveendra, and J.A. Attenhofer. "Design and Analysis of Retaining Wall Backfilled with Shredded Tire and Subjected to Earthquake Shaking.” Soil Dynamics and Earthquake Engineering 90 (November 2016): 227239. doi:10.1016/j.soildyn.2016.08.034.

[21] Shrestha, S, and Ravichandran, N. "Performance of Retaining Wall Backfilled with Tire Aggregate under Static and Dynamic Loading Conditions: Conventional Designs and Finite Element Simulations." International Journal of Geotechnical Engineering (April 17, 2018): 1-13. doi:10.1080/19386362.2018.1460963.

[22] Ebeling RM, Morrison EE, Whitman RV, and Liam Finn WD. "A manual for seismic design of waterfront retaining structures.” US Army Corps of Engineers. Technical report ITL-92-11; 1992.1

[23] Trenter, NA. "Approaches to the Design of Cantilever Retaining Walls." Proceedings of the Institution of Civil EngineersGeotechnical Engineering 157, no. 1 (2004): 27-35.

[24] O'Sullivan, C, and Creed M. "Using a Virtual Back in Retaining Wall Design." Proceedings of the Institution of Civil Engineers-Geotechnical Engineering 160, no. 3 (2007): 147-51.

[25] American Association of State Highway and Transportation Officials (AASHTO). (2007). LRFD bridge design specifications, 4th Ed., AASHTO, Washington, D.C.

[26] EN 1998-5. Eurocode 8: Design Provisions for Earthquake Resistance of Structures, Part 5: Foundations, Retaining Structures and Geotechnical Aspects. Bruxelles: CEN, E.C. for Standardization; (2004).

[27] Forcellini, D., Tanganelli, M. and Viti, S., "Response site analyses of 3d homogeneous soil models", Emerging Science Journal, Vol. 2, No. 5, (2018), 238-250.

[28] Kloukinas, Panos, Anna Scotto di Santolo, Augusto Penna, Matthew Dietz, Aldo Evangelista, Armando Lucio Simonelli, Colin Taylor, and George Mylonakis. "Investigation of Seismic Response of Cantilever Retaining Walls: Limit Analysis Vs Shaking Table Testing." Soil Dynamics and Earthquake Engineering 77 (October 2015): $432-445$. doi:10.1016/j.soildyn.2015.05.018.

[29] Cavallaro, Antonio, Michele Maugeri, and Rosalia Mazzarella. "Static and Dynamic Properties of Leighton Buzzard Sand from Laboratory Tests.” (2001).

[30] PLAXIS. 2017. PLAXIS 2D Reference Manual, 2017. Delft: Plaxis.

[31] Hudson, M, IM Idriss, and M Beikae. "A Computer Program to Evaluate the Seismic Response of Soil Structures Using Finite Element Procedures and Incorporating a Compliant Base.” User's manual (1994).

[32] Hashash, Youssef M.A., and Duhee Park. "Viscous Damping Formulation and High Frequency Motion Propagation in NonLinear Site Response Analysis.” Soil Dynamics and Earthquake Engineering 22, no. 7 (September 2002): 611-624. doi:10.1016/s0267-7261(02)00042-8.

[33] Kuhlemeyer, Roger L, and John Lysmer. "Finite Element Method Accuracy for Wave Propagation Problems." Journal of Soil Mechanics \& Foundations Div 99, no. Tech Rpt (1973).

[34] Bathurst, R.J., and K. Hatami. "Seismic Response Analysis of a Geosynthetic-Reinforced Soil Retaining Wall.” Geosynthetics International 5, no. 1-2 (January 1998): 127-166. doi:10.1680/gein.5.0117.

[35] Matsuo, O., K. Yokoyama, and Y. Saito. "Shaking Table Tests and Analyses of Geosynthetic-Reinforced Soil Retaining Walls.” Geosynthetics International 5, no. 1-2 (January 1998): 97-126. doi:10.1680/gein.5.0116. 